\title{
ABSCESSO EPIDURAL DA COLUNA CERVICAL: RELATO DE CASO
}

\section{Epidural abscess of the cervical spine: case report}

Jenyffer Ribeiro Bandeira ${ }^{1}$, Jéssica Mendes Pereira ${ }^{2}$, Yasmin Batista de Paiva ${ }^{3}$, Bárbara Mamede Arrais ${ }^{4}$, Pedro Gonzalez Cuellar ${ }^{5}$.

\section{向 ACESSO LIVRE}

Citação: Bandeira RB, Pereira JM, De Paiva YB, Arrais BM, Cuellar PG. (2020) Abscesso epidural da coluna cervical: relato de caso . Revista de Patologia do Tocantins,7(1):. 127-129

Instituição: 1 Acadêmica do curso de Medicina da Universidade Federal do Tocantins, Palmas, Tocantins, Brasil. 2 Acadêmica do curso de Medicina do Instituto Tocantinense Presidente Antônio Carlos, Porto Nacional, Tocantins, Brasil. ${ }^{3}$ Acadêmica do curso de Medicina da Universidade de Gurupi, Gurupi, Tocantins, Brasil ${ }^{4}$ Acadêmica do curso de Medicina da Universidade Federal do Tocantins, Palmas, Tocantins, Brasil. ${ }^{5}$ Médico cirurgião geral, docente da Universidade Federal do Tocantins, Palmas, Tocantins, Brasil.

Este trabalho foi desenvolvido no Hospital Geral Público de Palmas Doutor Francisco Ayres.

\section{Autor correspondente: Jenyffer Ribeiro Bandeira. Endereço postal: quadra 806 sul, alameda 12, lote HM06, bloco 4, apartamento 202,

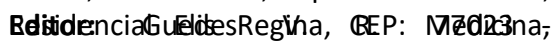

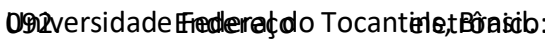 jenyffer61@gmail.com.}

Publicado: 09 de junho de 2019.

Direitos Autorais: (C) 2020 Bandeira et al. Este é um artigo de acesso aberto que permite o uso, a distribuição e a reprodução sem restrições em qualquer meio, desde que o autor original e a fonte sejam creditados.

Conflito de interesses: os autores declararam que não existem conflitos de interesses.

\begin{abstract}
RESUMO
Introdução: Os abcessos epidurais cervicais são formas raras de infecção, de difícil diagnóstico e tratamento. Cursa com complicações graves, como compressão da medula espinhal, resultando em danos irreversíveis. A prevalência desta patologia é maior no sexo masculino e a idade média de acometimento é de 50 anos. A região da coluna lombar é anatomicamente a mais acometida. Em cerca de $70 \%$ dos casos, o agente etiológico é o Staphylococcus aureus. Desenvolvimento: Paciente, masculino, 51 anos, foi admitido no hospital de referência de Palmas TO devido acidente motociclístico, apresentando fratura do processo órbitozigomático-maxilar esquerdo. No $8^{\circ}$ dia de internação, após cirurgia de osteossíntese dos ossos da face, evoluiu com cefaleia, parestesia e paresia de hemicorpo direito. A Tomografia de crânio não demonstrou alteração. O quadro clínico avançou com completa tetraplegia, quando foi identificado, por Ressonância magnética, a presença de abscesso cervical epidural. Foram realizadas Laminectomia e Laminoplastia Cervical sem melhora da quadriplegia. Considerações finais: Embora o abscesso epidural raquiano seja uma entidade rara, deve sempre ser lembrado como um possível diagnóstico, dado a sua rápida evolução, elevada morbidade e mortalidade. O grau de recuperação está diretamente ligado à rapidez do diagnóstico e inversamente à gravidade do estado neurológico.
\end{abstract}

Palavras- Chave: Abscesso; quadriplegia; abscesso epidural.

\section{ABSTRACT}

Introduction: Epidural cervical abscesses are rare forms of infection, difficult to diagnose and treat. It has serious complications, such as compression of the spinal cord, resulting in irreversible damage. The prevalence of this pathology is higher in males and the mean age of onset is $\mathbf{5 0}$ years. The lumbar spine region is anatomically the most affected. In about $70 \%$ of the cases, the etiologic agent is Staphylococcus aureus. Development: A 51-year-old male patient, was admitted to a reference hospital in Palmas - TO due to a motorcycle accident, presenting a fracture in the left zygomatic-orbital complex. On the 8th day of hospitalization, after the osteosynthesis surgery of the facial bones, he developed headache, paraesthesia and paresis of the right hemisphere. The cranial computed tomography scan showed no change. The clinical picture progressed to complete tetraplegia, when the presence of epidural cervical abscess was identified by the magnetic resonance imaging. Laminectomy and Cervical Laminoplasty were performed without improvement of quadriplegia. Final considerations: Although spinal epidural abscess is a rare entity, it should always be remembered as a possible diagnosis, due to its rapid evolution, high morbidity and mortality. The degree of recovery is directly related to the speed of diagnosis and inversely to the severity of the neurological state.

Keywords: Abscess; quadriplegia; epidural abscess. 
INTRODUÇÃO

Os abcessos epidurais são formas raras de infecção, com complicações graves, como compressão da medula espinhal, e danos irreversíveis, com difícil diagnóstico e tratamento. Em cerca de $70 \%$ dos casos, o agente etiológico é o Staphylococcus aureus. ${ }^{1}$

A prevalência dos abscessos epidurais cervicais (AEC) é maior no sexo masculino provavelmente devido a uma maior incidência de fatores predisponentes nesse gênero, como alcoolismo crônico, uso de drogas ilícitas e maior predisposição aos traumatismos. ${ }^{2}$

A idade média de acometimento da doença em questão está em torno dos 50 anos. Na última década, houve um aumento no número de casos por consequências do envelhecimento da população, disseminação do abuso de drogas endovenosas, emprego de imunossupressores, surgimento de agentes bacteriológicos mais agressivos e resistentes, melhores ferramentas de diagnóstico por imagem, novos procedimentos de instrumentação cirúrgica da coluna vertebral e a maior frequência do emprego da via epidural para administração de fármacos. ${ }^{3}$

O AEC pode se desenvolver por extensão de uma infecção adjacente (osteomielite vertebral e abscesso cutâneo); disseminação hematogênica de uma infecção distante (endocardite bacteriana, osteomielite de ossos longos, abscesso pulmonar); ou por inoculação direta (trauma, procedimentos invasivos). ${ }^{4}$

Os fatores locais predisponentes são cirurgia da coluna, injeções ou cateteres epidurais e traumatismos recentes. A associação com trauma fechado existe em até $15 \%$ dos casos, mas geralmente há uma fonte de infecção primária que pode ser identificada. Acredita-se que o trauma ocasione um hematoma epidural, e que este se infecte. ${ }^{5}$

O abscesso epidural pode apresentar-se de forma inespecífica, com queixas variáveis de dor, parestesias e sintomas constitucionais, seguidas de uma piora súbita e fulminante. $O$ sintoma mais comum é dor, seguido de febre. ${ }^{6}$ Em dois estudos retrospectivos recentes, a coluna lombar foi a região mais afetada. ${ }^{1,7}$

$O$ diagnóstico por imagem pode ser realizado por Mielografia Convencional, Tomografia Computadorizada (TC) preferencialmente com Mielografia associada (mielo-TC) e por Ressonância Magnética (RM), esta última é o exame de escolha. ${ }^{1,8}$

O tratamento ideal do AEC permanece controverso na literatura, alguns autores defendem a terapia conservadora (antibioticoterapia sistêmica) enquanto outros são a favores do tratamento cirúrgico (laminectomia). ${ }^{9} \mathrm{~A}$ descompressão cirúrgica está indicada na presença de déficit neurológico. Em pacientes sem sintomatologia neurológica, e em bom estado geral, o tratamento pode ser clínico. ${ }^{6}$

\section{RELATO DE CASO}

Paciente, B.P.C, 51 anos, masculino, solteiro, pardo, operador de máquinas, natural de Porto Nacional - TO, procedente e residente em Palmas - TO. Foi admitido no Hospital Geral Público de Palmas Doutor Francisco Ayres, encaminhado da Unidade de Pronto Atendimento, com história de acidente motociclístico e posterior amnésia (não soube relatar o que aconteceu). Referia perda da consciência logo após o ocorrido. Negava náuseas e vômito.

Ao exame físico, vias aéreas pérvias, sem colar cervical e headblock. Aparelho pulmonar com murmúrio vesicular presente bilateralmente, sem ruídos adventícios, boa expansibilidade pulmonar, ausência de dor e crepitação à palpação, percussão com som claro pulmonar. Hemodinamicamente estável, sem sinais de choque. Bulhas cardíacas normofonéticas de ritmo regular em 2 tempos. Abdome flácido e pelve estável. Glasgow 15, pupilas isocóricas e fotorreativas. Presença de escoriações na mão esquerda, além de edema e hematoma periorbital esquerdo com crepitações. Tomografia de face evidenciou fratura do processo órbito-zigomático-maxilar esquerdo (Figura 1).

No 8o dia de internação hospitalar (DIH), o paciente foi submetido à correção cirúrgica da fratura de face com osteossíntese do complexo órbito-zigomático-maxilar e coronoidectomia sob anestesia geral. No período de recuperação pós-anestésica, queixou-se de cefaleia, parestesia e paresia de hemicorpo direito, cuja suspeita inicial era de Acidente Vascular Encefálico (AVE). No entanto, a Tomografia de crânio não demonstrou alteração.

No dia seguinte, houve piora do quadro de parestesia e sobretudo paresia, afetando os quatro membros. O quadro estava associado a dor cervical intensa. 0 paciente desenvolveu humor deprimido e insônia. Ressonância de crânio e coluna cervical evidenciou alteração aos níveis das vértebras C5 e C6, interpretada como possível hematoma epidural cervical (Figura 2). O paciente então passou a utilizar colar cervical.

Dois dias após, o quadro evoluiu para tetraplegia, e então, foram realizadas Laminectomia e Laminoplastia Cervical, nas quais se encontrou secreção purulenta em região anterior de C3 a C6. A cultura do material drenado no procedimento cirúrgico não apresentou crescimento microbiano, assim como as duas amostras de hemocultura. A antibioticoterapia utilizada foi Cefepime e Linezolida, iniciada após o procedimento cirúrgico.

No 170 DIH, houve rebaixamento súbito do nível de consciência e necessidade de intubação orotraqueal por provável quadro séptico, ocorrendo transferência para a Unidade de Tratamento Intensivo (UTI). Na ausculta pulmonar, o murmúrio vesicular estava presente bilateralmente, porém diminuído em base de hemitórax esquerdo.

O paciente permaneceu internado até a estabilização do quadro - desmame de ventilação mecânica, oclusão da cânula de traqueostomia e tratamento das infecções pulmonar e de pele. Posteriormente, recebeu alta hospitalar, sem resolução da tetraplegia. 
ser esquecido. O diagnóstico precoce faz-se necessário, dada a sua rápida evolução e elevada morbimortalidade.

O caso relatado está na prevalência de sexo masculino maior que 50 anos, exposto a fatores predisponentes como o uso de bebida alcoólica associado à pilotagem de motocicleta. ${ }^{2}$ É um relato de acometimento da região anatômica menos afetada com a patologia, a região cervical. ${ }^{8}$

O agente etiológico dos abscessos cervicais mais prevalente é o S. aureus, seguido pelo Staphilococcus sp., dessa forma, a antibioticoterapia recomendada é a de amplo espectro com cobertura anti-estafilococo até que se tenha o resultado da cultura. Porém, em $40 \%$ dos casos, como no relato deste trabalho, não é possível identificar o microrganismo responsável. ${ }^{10}$

Como o abscesso epidural cervical é uma afecção rara, a primeira possibilidade de diagnóstico pensada foi o Acidente Vascular Encefálico, e então somente após o exame de imagem (RM) se considerou um hematoma epidural cervical que, na verdade, já havia evoluído para abscesso. Entretanto, a presença de um processo infeccioso, geralmente da pele, com sinais tóxicos - infecciosos, ou história de traumatismos, evoluindo rapidamente com dores sobre a coluna, dores radiculares e sinais de comprometimento medular são elementos clínicos para o diagnóstico do abscesso epidural. ${ }^{11}$

A evolução do primeiro sintoma para a tetraplegia foi demasiadamente rápida, cerca de dois dias. Este fato dificultou a compreensão da situação pelo paciente, que se imaginava muito bem, apenas esperando a cirurgia de correção da fratura de face, e se viu de repente naquela situação, desenvolvendo humor deprimido, ansiedade e insônia.

A possibilidade de total recuperação da função motora é extremamente baixa mesmo após a cirurgia, imobilização cervical e uso de antibióticos. As complicações estão principalmente relacionadas aos riscos de infecção generalizada e comprometimento respiratório. ${ }^{2}$

Embora o abscesso epidural raquiano seja uma entidade rara, deve sempre ser lembrado como um possível diagnóstico, dado a sua rápida evolução, elevada morbidade e mortalidade. $\mathrm{O}$ grau de recuperação está diretamente ligado à rapidez do diagnóstico e inversamente à gravidade do estado neurológico. ${ }^{11}$

$\mathrm{Na}$ suspeita diagnóstica de abscesso epidural cervical, os exames laboratoriais, principalmente Proteína C - Reativa e Velocidade de Hemossedimentação, e os de imagem (Ressonância de coluna cervical) devem ser realizados. 0 tratamento cirúrgico mediante laminectomia e laminoplastia descompressiva se impõe de imediato. ${ }^{2}$

\section{CONCLUSÃO}

Os abscessos epidurais são casos raros e de difícil diagnóstico. Tal fato justifica as limitações em se encontrar literaturas recentes que abordem o tema. No entanto, diante de uma sintomatologia neurológica súbita associado à uma tomografia de crânio normal, é um diagnóstico diferencial que não pode

\section{REFERÊNCIAS BIBLIOGRÁFICAS}

1. Shweikeh F, Saeed K, Bukavina L, et al. An institutional series and contemporary review of bacterial spinal epidural abscess: current status and future directions. Neurosurg Focus. 2014 Aug;37(2):1-11.

2. http://dx.doi.org/10.3171/2014.6.FOCUS14146

3. Pereira CU. Abscesso extradural da coluna vertebral revisão de literatura. Arquivos Brasileiros de. Neurocirurgia. 2012 Mar;31(1):34-40.

4. http://dx.doi.org/10.1055/s-0038-1625656.

5. Lima FMT, Silva JC. Abscesso epidural raquiano piogênico. Arq Bras de Neurocir. 2001 Mar;18(1/2):51-55.

6. http://dx.doi.org/10.1055/s-0038-1623469.

7. Pippo $A$, Legnani $M$, Mérola $V$, et al. Empiema epidural espinal: clínica, diagnóstico y tratamiento a propósito de tres casos. Rev. Méd. Urug. 2015 Nov;31(4):289-292.

8. Vialle $E$, Vialle LR, Holtmann G. Abcesso epidural póstraumático. Acta Ortop Bras. 2008;16(5):311-13.

9. http://dx.doi.org/10.1590/S1413-78522008000500012

10. Curry WT, Hoh BL, Hanjani SA, et al. Spinal epidural abscess: clinical presentation, management and outcome. Surg Neurol. 2005 Apr;63(4) 364-71.

11. http://dx.doi.org/10.1016/j.surneu.2004.08.081.

12. Vakili M, Crum-cianflone NF. Spinal Epidural Abscess: a Series of 101 Cases. The American Journal of Medicine. 2017 Dec;130(12):1458-1463.

13. http://dx.doi.org/10.1016/j.amjmed.2017.07.017.

14. Sendi $P$, Bregenzer T, Zimmerli W. Spinal epidural abscess in clinical practice. QJM: An International Journal of Medicine. 2008 Jan;101(1):1-12.

15. http://dx.doi.org/10.1093/qjmed/hcm100.

16. Yang X, Guo R, Lv X, et al. Challenges in diagnosis of spinal epidural abscess: A case report. Medicine (Baltimore). 2019 Feb;98(5):e14196.

17. http://dx.doi.org/10.1097/MD.0000000000014196

18. Vialle $E$, Vialle LR, Holtmann G. Abscesso epidural póstraumático. Acta Ortop Bras. 2008;16(5):311-13.

19. http://dx.doi.org/10.1590/S1413-78522008000500012

20. Braga FM, Ferraz FAP, Jordy CF. Abscessos epidurais raqueanos - registro de cinco casos. Arq. Neuro-Psiquiatr. 1981;39(2):192-202.

21. http://dx.doi.org/10.1590/S0004-282X1981000200008. 